\title{
How an Aging Population in Slovakia Impacts the Utilization of the Current Array of Long-Term Care Services (Review)
}

K. Whitehead (Kendall Whitehead)

University of Scranton, PA, U.S., Master of Health Administration

Graduate Program, USA

\section{E-mail address:}

kendall.whitehead@scranton.edu

\section{Reprint address:}

Kendall Whitehead

University of Scranton, PA

Scranton Hall

Scranton, PA 18510

USA

Suource: Clinical Social Work and Health Intervention

Pages: $92-98$

Volume: 8

Issue: 4

\section{Reviewers:}

Michael Costello

University of Scranton school of education, USA

Harald Stefan

Vienna General Hospital, Vienna, AT

\section{Key words:}

Long-Term Care Services. Slovakia. Aging Population. Impacts.

\section{Publisher:}

International Society of Applied Preventive Medicine i-gap

CSWHI 2017; 8(4): 92 - 98; DOI 10.22359/cswhi_8_4_13 @ 2017 Clinical Social Work and Health Intervention

\section{Abstract:}

Objective: The aim of this research is to analyze aging population demographics compared to the current demand of long-term care services available in the Slovak Republic.

Methods: This paper is a secondary source research study augmented by person to person conversation with Slovak Doctoral Students at Trnava University. 
Results: The Slovak government should increase efforts to integrate both the social and medical healthcare spheres.

Conclusion: The study indicated that the Slovak Republic is experiencing an aging population and may not be able to accommodate elders in the future due to an increased demand for services. There is opportunity for growth within the informal caregiving sector by increasing support and education. Increasing preventative and ambulatory care services can ensure accessibility and more medical staff educated in the field of Geriatrics. There is an opportunity to conduct more research on future long-term care trends.

\section{Introduction}

Almost every country in the world is experiencing an aging population. The increasing share and proportion of people aged 65 years or older is drastically changing the social sphere of every country. Population aging includes implications for nearly all sectors of society. Preparing for a dramatic social change is essential to ensure a country's continuous development. This causes a need to identify specific impacts and propose solutions to respond to the changes.

Countries all over the world are experiencing shifts in long-term care due to an aging population. This shift is inevitable and known as a "demographic revolution, characterized by low birth and death rates respectively to prolong human life" (Pavelek, Eidenmueller, 924). Aside from an aging population, technological and scientific advancements have also contributed to mortality decline, ultimately influencing better health and longevity. The elderly population as a whole is defined as persons aged 65 years or older. People aged 65-74 are known as "young-old," while those aged 75 or older are known as "old-old" (Pavelek, Eidenmueller, 925). This is causing long-term care to become one of the fastest growing sectors in healthcare today.

\section{Demographics}

The Slovak Republic, like many Central European countries, is experiencing an aging population. Currently, there are approximately 5,433,381 people living in the Slovak Republic. According to Eurostat: Population Structure and Aging, in 2015, persons aged 65 years or older accounted for approximately $14 \%$ of the total population. By 2025 , that $\%$ age will rise to $18.1 \%$, and by $2050,24.8 \%$ of the population. Currently among the top five youngest countries in Europe, the Slovak Republic will become the oldest country in Europe by 2080. According to Eurostat: Population Structure and Aging, the median age of the Slovak Republic in 2016 was 40.1 years old, while in 2080, the median age is expected to rise to 53.7 years, a 13.6-year difference.

An old age dependency ratio is a ratio of elders, or those not currently active in the workforce, to the working age population, which is often defined as ages 15-64. This ratio is defined as the amount of persons aged 65 years or older for every 100 working age persons in a given population. According to Eurostat, in 2010, persons aged 15-64 accounted for approximately $73 \%$ of the population. By 2050 , that \%age is expected to decrease to $57 \%$ of the population, a $16 \%$ age point decline. As of 2015 , there were 19.8 persons aged 65 years or older per 100 working age persons, or a 1 to 5 
ratio. By 2060, there will be 57.2 persons aged 65 or older per every 100 working age people, or a 1 to 2 ratio. With this increase, there will be greater pressure placed on the productive part of the population to provide goods for themselves and also the older portion of the population (Eurostat).

Currently, out of the Slovak Republic's population, approximately 770,000 people are aged 65 and older. Of those 770,000 people, approximately 200,000 people require long term care services. Of those, approximately 38,000 receive formal, institutional medical care, 70,000 receive formal, homebased social services, and 61,000 receive informal care provided by informal caregivers. Thus, approximately 31,000 elders, or $15.5 \%$ do not receive the proper care they need (The Long-Term Care System for the Elderly in Slovakia, 11).

\section{Long-Term Care Services}

The current array of long-term care services in the Slovak Republic is represented by two main spheres - social care services and healthcare services. Social care services aim to rehabilitate a dependent person to live a more independent life. These services are concerned with alleviating unfavorable social situations for a dependent person. Social care services consist of outpatient, inpatient, and home care, including supported living facilities, nursing care facilities, facilities for seniors, social housing, day care facilities, community care, social rehabilitation, retirement homes, and informal home care (The Long-Term Care System for the Elderly in Slovakia, 6-7).

Healthcare, also known as institutional medical care, is provided for people who need care for twenty-four hours per day or longer. These services include inpatient and outpatient care such as medical facilities, ambulatory care, mobile hospice care, nursing homes, hospitals, long-term care departments, and sanatoriums (The Long-Term Care System for the Elderly in Slovakia, 4-5).

Another category, which stems from social care services, is known as informal care. Informal care is provided by informal caregivers who are typically relatives, close friends, or neighbors of a dependent person. These services are paid on a monthly basis depending the elder's level of dependency. There are approximately 59,000 informal caregivers caring for 61,000 elders receiving informal care. $52 \%$ of informal caregivers are between the ages of 51 to 64 . Women account for about $84 \%$ of caregivers, while men only account for a mere $16 \%$. There is a lack of men in informal caregiving (The Long-Term Care System for the Elderly in Slovakia, 3).

To determine which services are provided to a dependent person, an assessment of their level of dependency and level of needs is addressed. Their level of disability is determined by their activities of daily living (ADL). A six-grade scale is assessed by an advisory committee comprised of Physicians and Social Workers. Act No. 448/2008 defines 12 criteria for ADLs, such as eating, drinking, sitting, walking, personal hygiene, washing, and orientation. The dependent person is then scored from zero to ten on their assessment of needs. The higher the degree of dependency, the more likely a person will be provided with institutional medical care. Due to limited capacity, the preferred outcome is providing the dependent person with social service needs or informal caregiving (Long Term Care of the Elderly, 96).

\section{Barriers to Long-Term Care}

There are four potential barriers to the long-term care system in the Slovak Republic. There are governmental barriers, organizational barriers, financial pressures, and increasing pressure on informal caregivers. 
There are governmental barriers to longterm care. There are legislative issues that arise when elders are using both spheres - social care and healthcare - in long-term care. Both systems are regulated by different acts, regulations, and legislature, which may not always be linked together, nor cover all services provided. Some acts have been prepared to combine both systems, but these acts were not approved (The LongTerm Care System for the Elderly in Slovakia, 17). Several acts have been put in place, however, social care and healthcare is not systematically regulated.

Since 2000, the Slovak Government has made efforts towards improving the legislature for long-term care. In August 2000, the National Action Program for the Protection of Elderly People, or NAPPEP, was approved (OHCHR). The aims of this program were to help elders live an independent life, inclusion in social participation, integration into society, and autonomy. The goal of the program was to prepare society for an aging population. This program addressed five key principles for elders - the principle of independence, participation, caring, self-realization, and dignity (OHCHR). In November 2000, the State Policy of Health in the Slovak Republic was approved. This policy defined three long-term care priorities: enhancing healthy aging, developing and increasing palliative care, and improving mental health (Government of the Slovak Republic, 2000).

Although improvement efforts were gaining headway in the early 2000 s, much of the government's success efforts ended by 2005. A legislative act to support long-term care and disabled persons was prepared in 2004 but was never approved by the government. In 2005, the Slovak government approved the Strategy on Healthcare for Geriatric Patients and Long-term Patients and the Conception of Social and long-term Care in the Slovak Republic, but the proposals for the acts stopped by the end of 2005 (The Long-Term Care System for the Elderly in Slovakia, 16). There are also efforts to create "amendments and reparations that aim to equalize providers of Social Services, but lack of financial resources in budgets of self-governing regions and municipalities creates a non-equal environment for private social care providers" (Long-Term Care of the Elderly, 88).

There are also organizational barriers within the long-term care system. With two separate sectors providing care to elders, there is little coordination between the two. In the early 2000s, the Slovak Republic's Government began efforts to integrate both sectors to create one integrated model of social and long-term medical care. However, in 2005, these integration efforts were stopped. To integrate these models, both sectors should first be improved (The LongTerm Care System for the Elderly in Slovakia, 16).

There are financial pressures on the long-term care system in the Slovak Republic. With the increase in services needed in the near future to accommodate the aging population, there is a demand on revenues from the working age population. However, revenues are expected to decrease due to a decline in the working age population over the next fifty years. The reduction of the working age population is expected to also cause a decline in the average annual GDP (OECD, 2012). This decline will add additional pressure to the health system and may need to create measures to keep people in the work force longer (WHO, 2009).

\section{Solutions and Opportunities}

With a lack of information, there is an opportunity to conduct more research on future long-term care trends in the Slovak Republic. The long-term care system is in need of simplification and unification. Current future 
needs are not well-defined and should be further addressed to accommodate future trends in an aging population. Since the Velvet Revolution, healthcare, especially long-term care, has been in a transitional period. Tasks and priorities need to be addressed for future needs (The Long-Term Care System for the Elderly in Slovakia, 14). Some possible solutions to address the expanding need are providing additional support, information, and education for informal caregivers, creating an integrated model of care, focusing on additional needs in preventative, ambulatory, geriatric care, and increasing additional institutional capacities.

Additional support, information, and education should be provided to those providing care to their loved one. Currently, informal caregivers are not required to have any special qualifications or training to provide care. Measures should be put in place to provide assistance to those providing care, such as training, counseling, or coaching from healthcare professionals. Classes can be held at local healthcare organizations to teach caregivers the most efficient ways of providing care. In addition, men should be encouraged to participate in caregiving (OECD).

The Slovak Republic should work towards integrating both the social and medical sector under one joint model. There is currently a wide variety of services offered within the social sector, but these services will need to be simplified to fit with the institutional, medical sector (The Long-Term Care System for the Elderly in Slovakia, 6). To integrate these models, both sectors need improvements under the authority of both ministries. The social care sector will require additional resources in the future to accommodate the increasing elder population. The institutional, medical care sector should aim to reduce the supply of medical care. There is opportunity to provide integrated services, but, currently, the Slovak
Republic's long-term care facilities do not fulfil the criteria to do so (The Long-Term Care System for the Elderly in Slovakia, 16).

There is also an opportunity to provide additional needs in preventative care, ambulatory care, and institutional, geriatric healthcare, as stated in the Conception of Social and Long-Term Care (Government of the Slovak Republic, 2005b) and Strategy of Health Care for Geriatric Patients and Long-Term Patients in the Slovak Republic (Government of the Slovak Republic, 2005a).

In these needs, additional institutional capacities should be met. Preventative care puts an emphasis on preventative programs such as The National Cardiovascular Program, Oncologic Program, and free vaccinations for people 65 years of age or older. These programs should be continued based on needs, and there should be increased knowledge about the importance of taking preventative action. This could ultimately reduce the number of elders using institutional, medical care in the future if their illnesses are prevented. From a global perspective, increased attention should be placed on preventing infectious disease (Skolnik, 26).

Ambulatory care also requires an additional focus. According to page 15 of The Long-Term Care System for the Elderly in Slovakia, Practitioners should place an emphasis on improvingthe care and maintenance of chronic diseases, while working closely with nursing care agencies and other social care facilities. There should also be increased availability of ambulatory care services in all 79 counties of the Slovak Republic. This will ensure accessibility to care and increased medical staff educated in the field of Geriatrics (The Long-Term Care System for the Elderly in Slovakia, 15).

For those who have chronic conditions and need prolonged medical care, there is institutional and geriatric medical care, which is provided in geriatric departments 
of hospitals and sanatoriums. Increased bed capacity and facilities for palliative care and hospice are needed to address the increase in demand. According to the Ministry of Health, there should be at least one geriatric department in each region in the Slovak Republic, along with an increase in Geriatric Specialists (The Long-Term Care System for the Elderly in Slovakia, 16).

\section{Conclusion}

An aging population presents challenges within the Slovak Republic's long-term care system and will have a major impact on the delivery of care in the future. Population aging presents new philosophies on the relationships between the delivery of social and medical care. While there had been legislative changes in the past, the long-term care system has not been an established concept and is currently integrated into different sectors of healthcare. Knowledge is limited on good practice policies and future trends. This fragmentation hinders the development of the healthcare system, the communication between sectors, and limits the opportunity to measure and evaluate long-term care trends.

These demographic changes present opportunities for improvement within the Slovak Republic's long-term care system. There is a greater need to recognize and prepare for the integration of the social care and medical care sectors. This integration could reduce the need for medical care and provide the social care system with additional resources. It is important to recognize the role of caregivers within the social care sector. The increase of informal care givers through awareness and support will run parallel with the increase of the population. Lastly, an increased emphasis on preventative programs, ambulatory care, and geriatric health could increase the capacity of services and may prevent elders from needing care.
An aging population, the need for an integrated model, and the need for greater availability of service capacities will further place pressure on the Slovak Republic's long-term care system. This provides greater opportunity to respond to these needs and prepare for increasing population trends.

\section{References}

1. BAUER J M, SOUSA-POZA A (2015) Impacts of Informal Caregiving on Caregiver Employment, Health, and Family. Journal of Population Ageing 8.3. 113-45. Forschungsinstitut Zur Zukunft Der Arbeit Institute for the Study of Labor. Web. 15 Apr. 2017.

2. EUROPEAN COMMISSION (EDS.) (2011) Strategy for equality between women and men 2010-2015. EC, Luxembourg.

3. GAUtun H, HAGEN K (2007) A Moral Squeeze? Does the Supply of Public Care Services Towards the Very Old Affect Labor Force Participation of their Children? Paper presented 8th Congress of the European Sociological Association, Glasgow, 3-6 Sept. Research Network Session: Ageing in Europe Session 5a Norms and Values in Ageing.

4. GOVERNMENT OF THE SLOVAK REPUBLIC (2000) State Policy on Health in the Slovak Republic, Bratislava. Input of the Slovak National Centre for Human Rights to the Request of United Nations. Independent Expert on the Enjoyment of All Human Rights by Older Persons Concerning Human Rights Implications of the Implementation of the Madrid International Plan of Action on Ageing (MIPAA). (2016). $O H C H R$. Slovak National Center for Human Rights,Web. 14 Apr. 2017.

5. MACKOVA M (2013) Long Term Care of the Elderly. 1st Ed. N.p.: Tribune EU Brno, Tribune EU Brno. Web. 10 Apr. 2017.

6. OECD (2012) Looking to 2060: A Global Vision of Long-Term Growth, OECD 
Economics Department Policy Notes, No. 15 November 2012.

7. OSTERLE A (2011) Long-term Care in Central and South Eastern Europe. Frankfurt Am Main: Peter Lang. Print.

8. PAVELEK L, EIDENMUELLER T (2014) The current status, prospects and characteristics of population ageing in slovak republic. EconPapers 10: 923-30. Web. 02 May 2017. Policies to Support Family Carers. Help Wanted? OECD Health Policy Studies (2011): 121-58. Oecd.org. Web. 14 Apr. 2017.

9. RADVANSKY M, PALENIK V (2010) The Long-term Care System for the Elderly in Slovakia. Brussels: ENEPRI, European
Network of Economic Policy Research Institutes. Web. 17 Apr. 2017.

10. BERND R, DOYLE Y, GRUNDY E, MCKEE M (2016) How Can Health Systems Respond to Population Aging? Health Systems And Policy Analysis (2016): n. pag. WHO Regional Office for Europe and European Observatory on Health Systems and Policies. Web. 20 Apr. 2017.

11. SKOLNIK R (2016). Global Health 101. Jones \& Bartlett Learning, Print.

12. SOPOVA M (2013). Social Services System Reforms in Slovakia, and Transformation of Social Service. Social Services System in Slovakia - Part 1, Social Services Systems in Slovakia Web. 2 May 2017. 